\title{
Review
}

\section{Ovarian Cancer Development and Metastasis}

\author{
Ernst Lengyel \\ From the Department of Obstetrics and Gynecology/Section of \\ Gynecologic Oncology, University of Chicago, Chicago, Illinois
}

The biology of ovarian carcinoma differs from that of hematogenously metastasizing tumors because ovarian cancer cells primarily disseminate within the peritoneal cavity and are only superficially invasive. However, since the rapidly proliferating tumors compress visceral organs and are only temporarily chemosensitive, ovarian carcinoma is a deadly disease, with a cure rate of only $30 \%$. There are a number of genetic and epigenetic changes that lead to ovarian carcinoma cell transformation. Ovarian carcinoma could originate from any of three potential sites: the surfaces of the ovary, the fallopian tube, or the mesothelium-lined peritoneal cavity. Ovarian cacinoma tumorigenesis then either progresses along a stepwise mutation process from a slow growing borderline tumor to a well-differentiated carcinoma (type I) or involves a genetically unstable high-grade serous carcinoma that metastasizes rapidly (type II). During initial tumorigenesis, ovarian carcinoma cells undergo an epithelial-to-mesenchymal transition, which involves a change in cadherin and integrin expression and upregulation of proteolytic pathways. Carried by the peritoneal fluid, cancer cell spheroids overcome anoikis and attach preferentially on the abdominal peritoneum or omentum, where the cancer cells revert to their epithelial phenotype. The initial steps of metastasis are regulated by a controlled interaction of adhesion receptors and proteases, and late metastasis is characterized by the oncogene-driven fast growth of tumor nodules on mesothelium covered surfaces, causing ascites, bowel obstruction, and tumor cachexia. (Am J Pathol 2010, 177:1053-1064; DOI: 10.2353/ajpath.2010.100105)

In 2009, the American Cancer Society reported 21,550 cases of epithelial ovarian carcinoma and 14,600 disease-related deaths, identifying ovarian carcinoma as the gynecologic malignancy with the highest case-to-fatality ratio. ${ }^{1}$ Sixty-nine percent of all patients with ovarian carcinoma will succumb to their disease, as compared with
$19 \%$ of those with breast cancer. The high mortality of this tumor is largely explained by the fact that the majority (75\%) of patients present at an advanced stage, with widely metastatic disease within the peritoneal cavity. Ovarian carcinoma metastasizes either by direct extension from the ovarian/fallopian tumor to neighboring organs (bladder/colon) or when cancer cells detach from the primary tumor. Exfoliated tumor cells are transported throughout the peritoneum by physiological peritoneal fluid and disseminate within the abdominal cavity. Extensive seeding of the peritoneal cavity by tumor cells is often associated with ascites, particularly in advanced, high-grade serous carcinomas. These cancers grow rapidly, metastasize early, and have a very aggressive disease course. Unlike most other cancers, ovarian carcinoma rarely disseminates through the vasculature. However, pelvic and/or para-aortic lymph nodes can be involved. ${ }^{2}$

Usually, patients with ovarian carcinoma have locally advanced disease in the pelvis, with contiguous extension to, or encasement of, the reproductive organs (uterus, fallopian, tube, ovaries) and the sigmoid colon. The omentum, normally a soft $20 \times 15 \times 2$-cm fat pad covering the bowel and the abdominal cavity, is almost always transformed by tumor. This generally causes the patient significant pain because the omental tumor tends to obstruct the stomach and the small and large bowel. Current treatment strategies for advanced ovarian carcinoma consist of aggressive surgery ("cytoreduction" or "tumor debulking"). To clear the cancer in the pelvis, surgery often involves an en bloc resection of the ovarian tumors, reproductive organs, and the sigmoid colon, with a primary bowel reanastomosis ("posterior exenteration"). This is technically possible because ovarian tumors stay within the peritoneal cavity, only invade the mesothelium- lined surface, and grow above the peritoneal reflection in the pelvis. Even large omental tumors

Supported by grants from the Ovarian Cancer Research Fund (Liz Tilberis Scholars Program), the National Cancer Institute (R01 CA111882), and Bears Care. Ernst Lengyel holds a Clinical Scientist Award in Translational Research from the Burroughs Wellcome Fund.

Accepted for publication May 10, 2010.

Address reprint requests to Ernst Lengyel, M.D., Ph.D., Department of Obstetrics and Gynecology/Section of Gynecologic Oncology, University of Chicago, MC2050, 5841 S. Maryland Ave., Chicago, IL 60637. E-mail: elengyel@uchicago.edu. 
only invade the superficial bowel serosa and never the deeper layers, which is why removal of the transverse colon is rarely necessary. ${ }^{3}$ The surgical treatment goal is to remove as much tumor as possible, because several studies have convincingly shown that cytoreduction results in improved patient survival. ${ }^{4,5}$

This effect of cytoreduction is indicative of a dramatic difference in the biological behavior of ovarian cancer as compared with other malignancies, because in most other cancers the removal of metastatic tumors has not been found to improve survival. Postoperatively, all women, except those with very well-differentiated earlystage cancer, receive chemotherapy with platinum (carboplatin, rarely cisplatin) and a taxane (Taxol, rarely taxotere). The optimal route of administration is still a matter of significant debate, but there is increasing evidence that in patients who have undergone optimal debulking (no residual tumor $>1 \mathrm{~cm}$ ), intraperitoneal (i.p.) delivery of these drugs increases progression-free survival by 5 months and overall survival by 15 months when compared with i.v. administration. ${ }^{6}$ The rationale for this treatment modality is based on the observation that ovarian carcinomas are generally restricted to the abdominal cavity and on pharmacodynamic studies that show that i.p. chemotherapy can achieve very high peritoneal drug concentrations.

\section{Pathology and the Site of Origin}

The World Health Organization has categorized ${ }^{7}$ epithelial ovarian carcinoma (which represents $80 \%$ of ovarian cancers) according to the predominant epithelial cell type (Figure 1). Thus, serous carcinoma has, when well or moderately differentiated, often a glandular or papillary architecture that resembles the papillary surface epithelium of the fallopian tube, (Figure 1, A-J) which is why it is also referred to as serous-papillary ovarian carcinoma. Endometrioid carcinoma, which is composed of endometrioid-like glands, is often associated with endometriosis and resembles endometrioid carcinomas of the uterus (Figure 1, K-M). Mucinous carcinomas resemble, in more well-differentiated areas, either endocervical glands or gastrointestinal epithelium (Figure 1, N-R). It is sometimes difficult to differentiate ovarian carcinomas from tumors of the gastrointestinal tract (eg, colon) that have metastasized to the ovary, but immunohistochemical staining for cytokeratin 7 and 20 (CK7 and CK20) may assist in their identification. Serous ovarian carcinomas are often CK7 positive and CK20 negative, whereas gastrointestinal carcinomas tend to be CK7 negative and CK 20 positive (Figure $1, I$ and $\mathrm{J}$ ). This expression pattern, however, is not always organ specific, because colon and gastric adenocarcinomas can express CK7, whereas $33 \%$ of mucinous ovarian adenocarcinomas are CK20 positive. The fourth major histological category is the clear-cell carcinoma of the ovary (Figure 1, S and T), a rare subtype also associated with endometriosis, which shares morphological features with both serous and endometrioid ovarian carcionoma. A very elegant gene expression study showed that genes expressed in different ovarian carcinomas are concordantly expressed in the normal tissues they resemble histologically. ${ }^{8}$

Three anatomical sites are the potential origin of highgrade serous carcinomas: the ovarian surface epithelium, the fallopian tube epithelium, and the mesothelium covering the surface of the peritoneal cavity. Over the past 40 years, the idea that the single layer of ovarian surface epithelium gives rise to serous carcinoma gained wide acceptance.9,10 The "incessant ovulation" theory holds that the frequent cycle of ovulation and surface repair, and the tendency of the ovarian epithelium to become trapped in inclusion cysts contribute to malignant transformation. The ovarian surface epithelium, a single layer of cells covering the ovary, is derived from the coelomic epithelium next to the gonadal ridge, whereas the uterus, cervix, and fallopian tube develop from the müllerian (paramesonephric) ducts. The ovarian surface epithelial cells express both epithelial (keratin) and mesenchymal (vimentin) markers, as do the mesothelial cells covering the peritoneum, pleura, and pericardium. Until recently, it was not clear how these epithelial cells could develop into müllerian-like tissues, when the epithelium is not of müllerian origin.

An elegant study out of Dr. Naora's laboratory examined HOX genes, which are involved in body segmentation and the morphogenesis of the different tissues in the female reproductive tract. ${ }^{11,12}$ HOX genes encode transcription factors that serve as master regulators for several genes important for morphogenesis. When HOXA9 was expressed in undifferentiated transformed mouse ovarian surface epithelial cells, these cells underwent differentiation and formed tumors that histologically resembled serous carcinomas. Similarly, the expression of HOXA10 induced an endometrioid-like ovarian carcinomas, and HOXA11 expression induced a mucinous like ovarian carcinoma. Although these data do not prove that ovarian carcinoma develops through this mechanism, it does show how the physiologically simple, undifferentiated ovarian surface epithelial cells may differentiate during transformation into a müllerian-like morphology, mimicking different epithelia of the reproductive tract.

However, because pathologists were generally unable to find an in situ ovarian lesion, doubt remained that ovarian carcinoma originates in the ovarian surface epithelium. Indeed, high-grade ovarian serous carcinoma is the only epithelial cancer currently without an established precancerous component. Recently, the fimbriael epithelium of the fallopian tube (Figure 1, $U-Z$ ) has been postulated as a possible site of origin for ovarian cancer, based on the observation by Piek et $\mathrm{al}^{13}$ that in BRCApositive patients the fimbriae often harbor a tubal intraepithelial carcinoma. ${ }^{14}$ The idea that far more sporadic serous cancers originate in the fallopian tube than was previously believed was further studied by Dr. Crum and his group. ${ }^{15,16}$ Complete sectioning of the fallopian tubes from 55 patients with pelvic serous carcinomas showed involvement of the inner lining of the fallopian tube in 41 (75\%). Most importantly, 29 (52\%) had tubal intraepithelial carcinomas, suggesting that the serous carcinomas had originated in the fallopian tube. The intraepithelial carcinomas found in the fallopian tube arose from secre- 
Normal fallopian tube

Serous ovarian borderline tumors

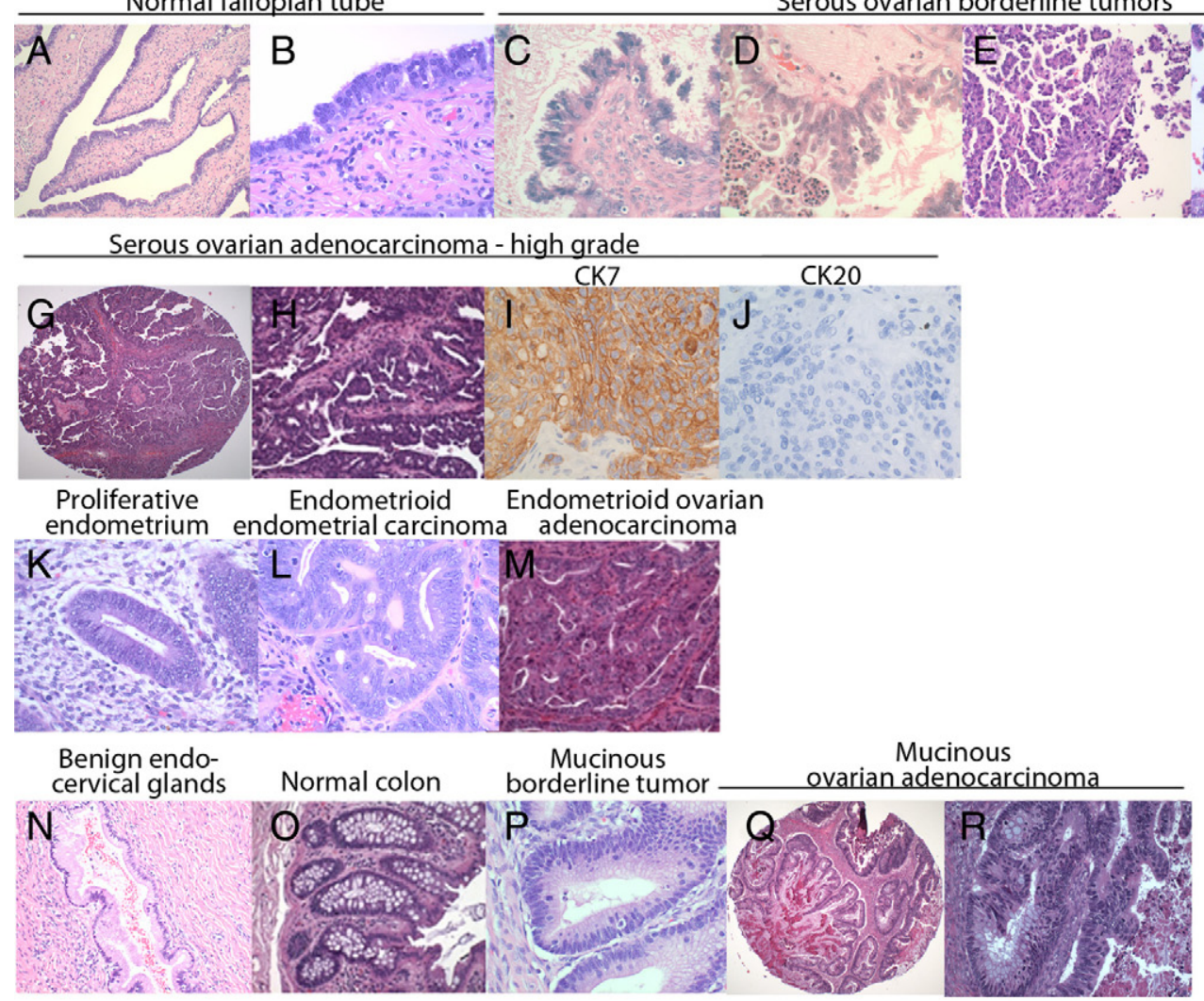

Clear cell ovarian adenocarcinoma

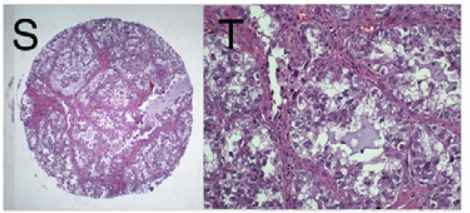

Fallopian tube with areas of dysplasia

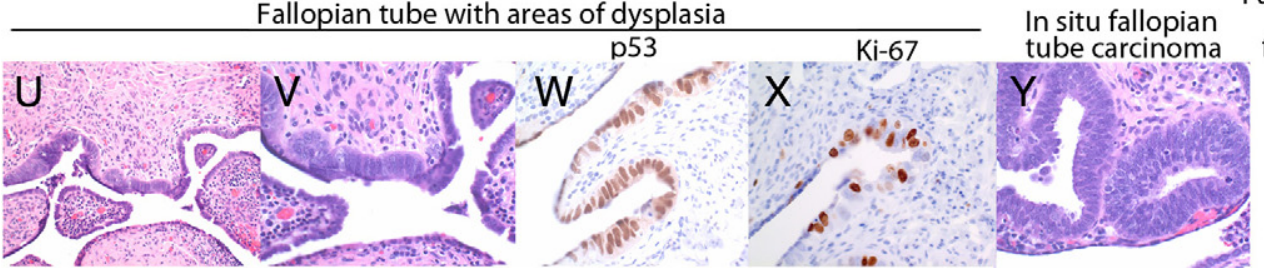

Fallopian tube with dysplasia (left transitioning into an invasive
fallopian tube carcinoma (right)

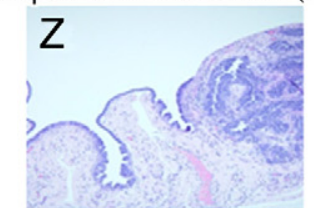

Figure 1. Major histological subtypes of borderline tumors, epithelial ovarian carcinoma, and the normal tissue they resemble. A and B: Normal fallopian tube at $\times 100$ (A) and $\times 400(\mathbf{B})$ magnification; C: serous borderline ovarian tumor at $\times 100$. D: Micropapillary, well-differentiated ovarian carcinoma ( $\times 400)$. E: Low-grade serous ovarian carcinoma $(\times 100)$. F: Low-grade serous ovarian carcinoma $(\times 400)$. G: High-grade serous ovarian carcinoma $(\times 100)$. H: High-grade serous ovarian carcinoma $(\times 400)$. High-grade serous carcinoma stained for cytokeratin $7(\times 400)(\mathbf{I})$ and in cytokeratin $20(\times 400)(\mathbf{J})$. K: Proliferative endometrium ( $\times 400)$. L: Endometrioid endometrial carcinoma, Grade I (×400). M: Invasive endometrioid ovarian carcinoma ( $\times 200)$. N: Benign endocervical glands ( $\times 200)$. O: Normal colon $(\times 200)$ P: mucinous borderline tumor $(\times 400)$. $\mathbf{Q}$ and $\mathbf{R}$ : Low-grade mucinous ovarian carcinoma at $\times 40(\mathbf{Q})$ and $\times 200(\mathbf{R})$ magnification. $\mathbf{S}$ and T: Clear cell carcinoma at $\times 40(\mathbf{S})$ and $\times 200(\mathbf{T})$ magnification. $\mathbf{U}$ and $\mathbf{V}$ : Fallopian tube with areas of dysplasia at $\times 100(\mathbf{U})$ and $\times 400(\mathbf{V})$ magnification. W: Fallopian tube with dysplastic epithelium that is p53 positive $(\times 400)$. X: Fallopian tube with dysplastic epithelium that is Ki-67 positive ( $\times 400)$. Y: In situ fallopian tube carcinoma $(\times 400)$. Z: Dysplastic fallopian tube transitioning into an invasive fallopian tube carcinoma $(\times 200)$

tory epithelial cells, exhibited strong p53 staining indicative of p53 inactivation/mutation, and overexpressed $\gamma$ - $\mathrm{H} 2 \mathrm{AX}$ protein, a surrogate marker for DNA damage in epithelial cells. ${ }^{15,16}$

Fallopian tube origin is also supported by a detailed understanding of pelvic organ embryology. Ovarian carcinomas (Figure 1, E-H) resemble histologically normal fallopian tube (Figure 1, A and B), endocervical glands and endometrium, (Figure $1 \mathrm{~K}$ ) sharing a common embryological origin in the müllerian duct, which is mesoder- mally derived. ${ }^{17}$ In contrast, the ovary and its covering surface epithelium are of coelomic origin, making it more difficult to understand how the epithelium transforms into a tumor that resembles tissues of the müllerian duct. Two hypotheses have been formulated to explain how both the fallopian tube and the ovary might contribute to tumorigenesis. The first speculates that at the transition of the fallopian tube and the ovary is an area of epithelial transition that is vulnerable to malignant transformation, very much like the transition zone of the cervix. ${ }^{18}$ The 
second theory posits that during ovulation, tubal epithelial cells from the fimbriae implant on the denuded surface of the ovary, resulting in the formation of inclusion cysts that become transformed in the ovarian microenvironment. ${ }^{19}$

\section{Genetic Insights into Ovarian Carcinoma Development: Two Major Subtypes of Ovarian Carcinoma}

In the last decade, significant progress has been made in our understanding of ovarian carcinoma tumorigenesis. The current working model, pioneered by Drs. Shih and Kurman, ${ }^{20,21}$ tries to match the different histological subtypes to genetic changes and conceptualizes two main molecular pathways that lead to ovarian carcinoma. The first category (type I cancers; Figure 1, C-F and M) is composed of low-grade serous-papillary, endometrioid, and borderline tumors of low malignant potential, and in the second category are the high-grade serous carcinomas (type II cancers; Figure 1, G-J). In general, the type I cancers are characterized by a young age at diagnosis, by an indolent disease course with a prolonged overall survival time (median 82 months), ${ }^{22}$ and by relative resistance to standard carboplatinum and Taxol chemotherapy. In contrast, the type II cancers, which are most prevalent in postmenopausal women, are initially very chemosensitive to platinum containing chemotherapy, but patients have a median survival of only 30 months.

The genetic changes in well-differentiated (Figure 1, E and F) serous neoplasms (type I tumors) seem to accumulate over time, transforming benign epithelium into a low-grade malignant tumor (Figure 1, A-F). They almost always arise within an existing serous neoplasm, usually a serous borderline tumor that has micropapillary architecture (Figure 1D). On histopathological examination, these carcinomas show the whole spectrum of epithelial differentiation, containing areas representative of benign serous cystadenomas, typical borderline tumors (Figure 1C), micropapillary borderline tumors (Figure 1D), and invasive well-differentiated carcinomas (Figure 1, E and F). Type I tumors typically have mutations in BRAF, KRAS, ERBB2, microsatellite instability, and follow the adenoma-to-carcinoma sequence first described for coIon cancer. ${ }^{23}$ Active mitogen-activated protein kinase is expressed in $>80 \%$ of these low-grade tumors, ${ }^{24}$ whereas it is expressed in $41 \%$ of high-grade serous tumors. As a consequence of these genetic insights, which suggest a prominent role for the Ras/Raf/mitogen-activated protein kinase pathway in ovarian carcinoma, the Gynecologic Oncology Group recently completed a clinical trial (GOG number 239) that studied the efficacy of an orally available non-ATP small molecule inhibitor of mitogen-activated protein kinase kinase in patients with recurrent low-grade invasive epithelial ovarian carcinoma.

The endometrioid (Figure 1M), mucinous (Figure 1, Q and R) and clear cell (Figure 1, S and T) histological subtypes of ovarian carcinomas share many genetic and clinical features with the type I carcinomas but have some distinct mutations and amplifications (eg, $\beta$-catenin, phosphatase and tensin homolog (PTEN) ${ }^{20,21}$ ) when compared with the well-differentiated serous carcinomas. KRAS mutations are very frequent in mucinous carcinomas. Clinically, both clear cell and endometrioid ovarian carcinomas share a common presentation: most patients present with early-stage disease that has rarely metastasized but has grown into one large ovarian tumor mass. In $20 \%$ of patients with endometrioid and clear-cell ovarian carcinomas, the disease is associated with endometriosis, which has been clearly identified as a precursor for both endometroid and clear-cell ovarian carcinoma. Loss of heterozygosity was detected in the same allele both in the tumor and in the adjacent endometriotic lesion of patients with these ovarian carcinoma subtypes. ${ }^{25}$ Also, endometriotic lesions and endometroid ovarian carcinoma share overexpression of a distinct set of genes (eg, SICA2, CCL14, and Cripto-1) that are not deregulated in serous carcinomas. ${ }^{26}$ The mutational data gathered in human cancer tissue from patients with endometrioid ovarian carcinomas were confirmed in a genetic mouse model of ovarian carcinoma. Expression of oncogenic KRAS or deletion of phosphatase and tensin homolog (PTEN) gave rise to endometriosis in the mouse ovary. When the two mutations were combined, the mice developed metastatic ovarian carcinoma, which often appeared endometrioid. ${ }^{27,28}$

The sequence of genetic events in high-grade serouspapillary carcinomas is not as well understood. Clinical experience and a recent study ${ }^{29}$ suggest that these tumors grow quickly and disseminate widely within the mesothelial cell-covered peritoneal cavity (or as an effusion in the mesothelial cell covered pleural space). Highgrade serous carcinomas show widespread DNA copy number gains and losses involving all chromosomes, which is a characteristic of their significant genetic instability. ${ }^{30,31}$ Kuo et $\mathrm{al}^{30}$ found reduced expression of RB1 and p16 protein in $>50 \%$ of all tumors and identified frequent homozygous deletions of RB1 and CDKN2A/B in $17 \%$ of serous carcinomas. Interestingly, a few years before their paper was published, deletion of RB1 and TP53 resulted in a mouse ovarian cancer model with serous histology. ${ }^{32}$ The most frequent genetic change in high-grade serous carcinomas involves p53 mutations, which occur in $50-80 \%$ of this form of cancer. ${ }^{33,34} \mathrm{Mu}-$ tations are found in tumors of all stages, suggesting that they originate in an early event in the progression of the disease. ${ }^{35}$ The timing of the mutation might explain why a large phase III trial of adenoviral wild-type p53 delivery combined with Taxol and carboplatinum did not show any positive results. ${ }^{36}$ Since p53 function loss leading to overexpression is seen in the earliest events of ovarian/ fallopian carcinoma tumorigenesis, including in situ cancers $^{15,16}$ (Figure $1 \mathrm{~W}$ ), it could be that once the tumor has metastasized and is chemoresistant (as were the patients enrolled on this trial) tumor growth no longer depends on p53.

Other important genetic alterations in high-grade serous tumors include BRCA 1 and 2 mutations and amplification of the AKT2 serine/threonine kinase and the phosphatidylinositol 3-kinase genes (40\%). ${ }^{37,38}$ Phos- 
phatidylinositol 3-kinase is mutated in one third of all clear cell ovarian carcinomas, but no amplifications have been detected in these cases. ${ }^{39}$ Because the AKT/phosphatidylinositol 3-kinase pathway is altered in a high percentage of type II ovarian carcinomas, several phosphatidylinositol 3-kinase inhibitors are in clinical development.

\section{Leaving the Primary Tumor: The First Step to Successful Ovarian Cancer Metastasis}

The biological behavior of ovarian carcinoma is unique, differing markedly from the classic and well-studied pattern of hematogenous metastasis found in most other cancers. For example, breast and colon cancer cells go through several steps of intra- and extravasation before they establish metastases within other organs (eg, bone, liver, brain). ${ }^{40}$ The task of metastasis appears to be easier for ovarian carcinoma. Once the cancer cells have detached as single cells or clusters from the primary ovarian tumor, it is thought that they metastasize through a passive mechanism, carried by the physiological movement of peritoneal fluid to the peritoneum and omentum. Clinical observation and retrospective clinical studies suggest that serous ovarian carcinomas grow very efficiently within the peritoneal cavity, but rarely metastasize outside of it. This was confirmed in patients who had peritoneovenous shunts implanted to palliate intractable ascites. The shunts, which were intended to relieve the discomfort of ascites without the risks associated with repeated paracentesis, infused billions of cancer cells into the venous system through the jugular vein. After up to 2 years of continuous shunting, most patients did not develop disseminated hematogenous metastases. ${ }^{41}$ This unusual result, a byproduct of a palliative clinical intervention, confirms that Paget's "seed and soil" theory holds true for ovarian carcinoma. The "soil" for ovarian carcinoma is the mesothelium (Figure 2A, B, and F) that covers all organs within the peritoneal cavity, including the omentum and the diaphragm. It is an interesting, but poorly understood, feature of ovarian carcinoma that the tumor implants invade the mesothelial cell layers (Figure 2, $\mathrm{D}$ and $\mathrm{E}$ ) but rarely invade deeper into the peritoneum.

Before the ovarian carcinoma cells detach and start their metastatic journey, they often undergo an epithelialto-mesenchymal (EMT) transition, which eases the attachment of epithelial cells to the basement membrane and loosens the intercellular adhesions between the cancer cells. One of the molecules critical for the adhesion of neighboring epithelial cells is E-cadherin, a membrane glycoprotein located at cell adherens junctions. ${ }^{42,43} \mathrm{E}$ cadherin connects through $\alpha$-and $\beta$-catenin to the actin microfilaments within the cytoplasm, thereby anchoring epithelial cells to each other. In general, loss of E-cadherin in epithelial cancer correlates with EMT and the acquisition of an invasive phenotype. ${ }^{44}$ In ovarian carcinoma, the E-cadherin expression of the cancer cells floating in ascites and at metastatic sites is lower than in the primary ovarian tumor. Moreover, ovarian carcinoma cells with low E-cadherin expression are more invasive ${ }^{45}$ and the absence of E-cadherin expression in ovarian carcinomas predicts poor patient survival. ${ }^{46}$ Loss of Ecadherin gene expression is mainly due to up-regulation of the zinc-finger containing transcriptional repressors Sip1/ZEB2, Snail, and Slug, which repress E-cadherin transcription. ${ }^{47}$

The following scenario summarizes our current understanding of epithelial-mesenchymal-epithelial "metamorphosis" during ovarian carcinoma metastasis. ${ }^{48,49}$ Initially, during malignant transformation, the epithelial cells undergo EMT, lose E-cadherin-mediated cell-cell interactions, and up-regulate other cadherins ${ }^{49,50}$ (eg, N-cadherin, P-cadherin) as part of a global "cadherin switch." The transformed cells, which now look more like fibroblasts, acquire an invasive phenotype and proliferate.
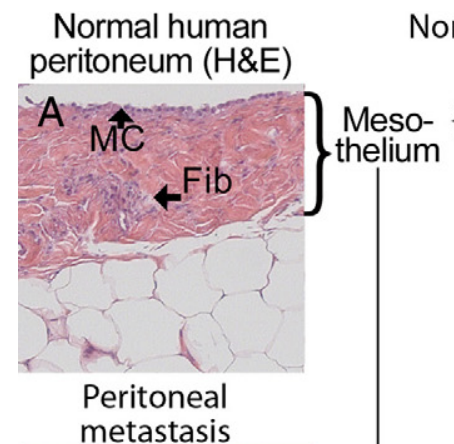

Normal human peritoneum Trichrome staining

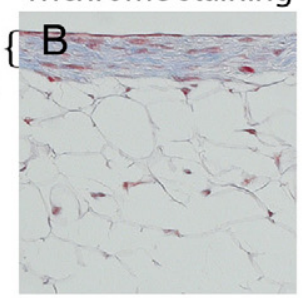

Normal human
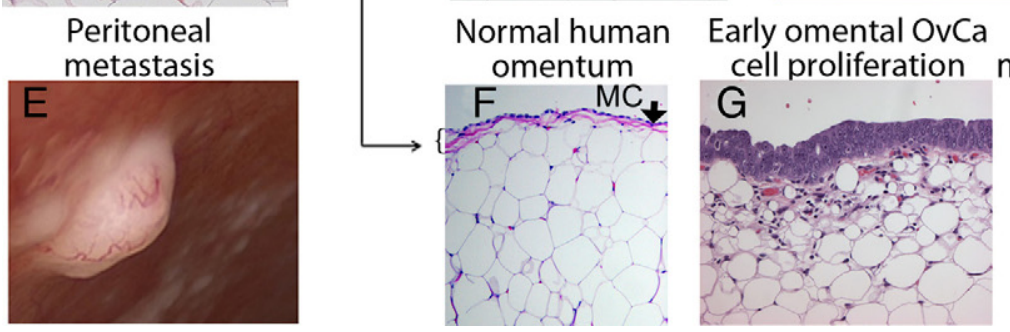

Peritoneal metastasis (white patches)
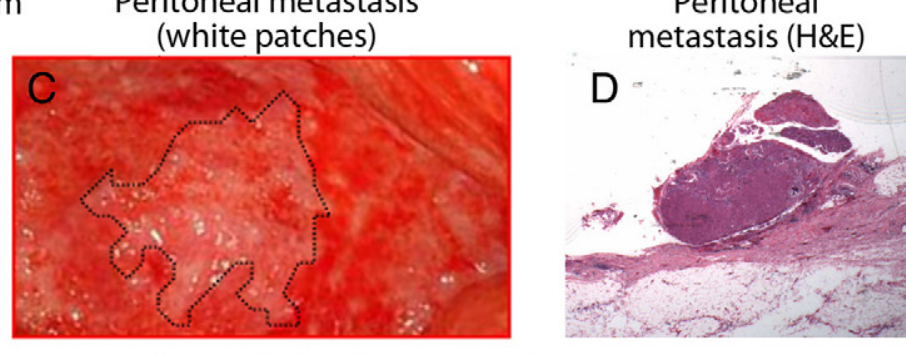

Later OvCa omental metastasis with invasion

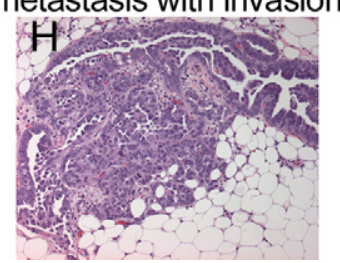

Figure 2. Serous ovarian carcinoma metastasis. Normal human peritoneum $(\times 200)$. A: H\&E staining. MC (mesothelial cells), Fib (fibroblasts). B: Trichrome staining to detect collagen. C: Photograph of peritoneal surface; implants (white patches) in a patient with disseminated ovarian carcinoma on a background of normal peritoneum (laparotomy). D: Implant in C. E: Peritoneal implant with neoangiogenesis. Other smaller implants in the background (laparoscopy). F: H\&E picture of normal omentum. G: Very early serous ovarian carcinoma (OvCa) metastasis on the omentum. Cancer cells proliferating on the surface of $\mathrm{f}$ the omentum without invading. H: Later phase: cancer cells invading into the omentum. 
EMT allows the cancer cells to survive under crowded hypoxic conditions ${ }^{51}$ and also allows mesenchymal signaling through interactions with surrounding stromal cells. Through clustering of collagen binding integrins ( $\alpha_{2} \beta_{1}$ - and $\alpha_{3} \beta_{1}$-integrin) on the cancer cell, matrix metalloproteinase (MMP)-9 is induced, which cleaves the E-cadherin ectodomain, contributing to the loosening of cell-cell adhesion and allowing the transformed cells to shed as single cells or spheroids into ascites. ${ }^{52}$ After the ovarian carcinoma cells have detached as single cells or clusters from the primary tumor, they spread to the peritoneum and omentum, carried by the physiological movement of peritoneal fluid. Within the spheroids the cancer cells maintain a mesenchymal phenotype ${ }^{53}$ and express Sip1, a known regulator of E-cadherin and MMP-2. As part of the EMT process, E-cadherin loss leads to transcriptional up-regulation of the fibronectin receptor, $\alpha_{5} \beta_{1}$-integrin, facilitating the adhesion of ovarian carcinoma cells to the secondary site. ${ }^{54}$ Once a metastatic colony is established in the omentum or peritoneum (Figure 2, D, F, and G), the ovarian carcinoma cells undergo mesenchymal-to-epithelial transition into an epithelial phenotype, which allows them to respond to paracrine growth factors and sustain fast growth.

It is not clear if ascites is present when tumor cells initially metastasize, or if ascites is a sign of a more advanced, high volume disease, as clinical studies and experience would suggest. ${ }^{55} \mathrm{~A}$ combination of factors can contribute to ascites formation in ovarian carcinoma. Cancer cells can obstruct subperitoneal lymphatic channels and prevent the absorption of the physiologically produced peritoneal fluid (1//day). Moreover, secretion of vascular endothelial growth factor (VEGF) by ovarian carcinoma cells increases vascular permeability and promotes the ascites formation. ${ }^{56}$ For this reason, inhibition of VEGF with an engineered soluble VEGF receptor (VEGF Trap) designed to bind all forms of VEGF-A inhibits ascites production very significantly in xenograft ovarian cancer mouse models ${ }^{57}$ and is now being tested in a clinical trial in advanced ovarian cancer patients with recurrent symptomatic ascites.

\section{Transit: Ovarian Cancer Cells Traveling as Single Cells and Spheroids within the Peritoneal Cavity}

Once the cancer cells have detached from the primary tumor, they float in the ascites as single cells or as multicellular spheroids. It is not clear whether single cells detach and then aggregate to form spheroids, or if the cells detach as cell clumps that stay together while floating in ascites. Several laboratories have established in vitro spheroid models from cultured ovarian carcinoma cells. ${ }^{58,59}$ A study of OVCAR- 5 spheroids demonstrated that $\alpha_{5} \beta_{1}$-integrin and its ligand, fibronectin, are present on the surface of the cancer cells. A function blocking antibody against $\beta_{1}$ integrin is able to inhibit spheroid formation, whereas $\beta_{1}$-integrin clustering antibody and fibronectin (both of which activate $\alpha_{5} \beta_{1}$-integrins) promote spheroid formation. ${ }^{60}$ That fibronectin plays an im- portant role in spheroid growth and attachment fits well with the current emphasis on the importance of the microenvironment in ovarian carcinoma metastasis, since several isoforms of fibronectin are abundantly present in ascites. Other integrins important in spheroid adhesion are $\alpha_{6} \beta_{1}$-integrin, which is known to bind laminin, and $\alpha_{2} \beta_{1}$-integrin, which binds to type IV collagen. ${ }^{59}$ Laminin, collagen, and fibronectin are not only present in ascites but are also the most abundant extracellular proteins in the mesothelium covering the peritoneum and the omentum. Given the integrin repertoire expressed on the spheroids, ovarian carcinoma cells are well equipped to adhere to these surfaces. In a study using cancer cell spheroids recovered from the ascites fluid of 11 patients, the spheroids showed very strong adhesion to fibronectin, type I collagen, and a monolayer of mesothelial cells. ${ }^{58}$

Proteolytic activity is also very important at multiple stages during the intraperitoneal metastases of spheroids, especially for their initial detachment from the surface of the ovary. Membrane type 1 MMP (or MMP-14) is a transmembrane protease phosphorylated at its cytoplasmatic domain. Active membrane type 1-MMP on cancer cells cleaves $\alpha_{3}$-integrin, contributing to the detachment of the spheroid from the primary tumor. ${ }^{61}$ membrane type 1-MMP continues to be expressed on spheroids even after they detach from the ovary, since it can be detected on spheroids in ascites from patients undergoing paracentesis. The other MMP expressed by the majority of multicellular aggregates collected from ascites is MMP-2, which plays a major role in early metastasis. ${ }^{62}$ The spheroids secrete more pro-MMP-2 than a monolayer culture made up of the same ovarian carcinoma cells. MMP-2 possibly promotes the fast disaggregation of the spheroids on adhesion to the surface mesothelial cell layer.

Several in vitro studies have explored the possibility that spheroids are less susceptible to chemotherapy than single cells, and it has been hypothesized that spheroids are resistant to anoikis because they express $\mathrm{BCl}-\mathrm{X}_{\mathrm{L}}{ }^{63}$ This raises the possibility that floating spheroids constitute a chemoresistant niche that continuously repopulates the abdominal cavity, making it impossible to cure ovarian carcinoma. Clinically, not much emphasis has been placed on ascites volume. Indeed, in clinical testing, new ovarian cancer agents are evaluated by assessing their impact on solid measurable disease. Since a number of published experimental studies emphasize the importance of adhesion molecules and proteases in spheroid formation, maintenance, and the subsequent adhesion of cancer cells at the secondary site, targeting their action makes biological sense. For example, disruption of E-cadherin-mediated adhesion and signaling in spheroids using an anti E-cadherin antibody re-sensitizes ovarian tumor cells to chemotherapy with Taxol. ${ }^{64}$

\section{Arrival}

Although ovarian carcinoma cells have the potential to metastasize throughout the peritoneal cavity, the organ 
distribution of ovarian carcinoma metastasis from the primary tumor is not completely random. Other than the fallopian tube and the contralateral ovary, the most common secondary sites for distant metastasis are the omentum (Figure 2, F-H) and the peritoneum (Figure 2, A-E). ${ }^{65}$ Within the peritoneum, which covers the entire abdominal cavity (a surface of $\sim 9 \mathrm{sq} f \mathrm{ft}$ in the average person), the right diaphragm and small bowel mesentery are preferentially colonized. We do not know if ovarian carcinoma cells arrive at the secondary site as single cells or as spheroids, or if the primary ovarian tumor prepares the omentum/peritoneum for successful colonization. It has been shown in other cancers that humoral factors secreted by the primary tumor mobilize bone marrow cells to prepare the metastatic niche. ${ }^{40}$

The primary microenvironment for the ovarian carcinoma cell is the mesothelium (Figure 2, A, B, and F), which covers all organs within the peritoneal cavity, including the diaphragms, bowel serosa, omentum, and the entire peritoneum. ${ }^{66,67}$ Histologically, the mesothelium is a single layer of mesothelial cells attached to a basement membrane predominantly composed of collagen types I and IV, fibronectin, and laminin. Fibroblasts and rare macophages are interspersed within this membrane and are responsible for producing several of the matrix proteins present. ${ }^{67-70}$

The first steps taken by the disseminated cancer cells when they home to the peritoneum and omentum involve an interaction between the cancer cell and the mesothelial cells covering the basement membrane. Integrins have been identified as important mediators of ovarian carcinoma metastasis to the mesothelium. $\beta_{1}$-Integrin, which can heterodimerize with many different $\alpha$-integrin subunits, is key to adhesion of ovarian carcinoma cells to mesothelial cells, as is evidenced by the fact that antibodies against $\beta_{1}$-integrin can inhibit adhesion. ${ }^{71} \mathrm{An}$ other important adhesion receptor, vascular cell adhesion molecule-1, (VCAM-1) is present on mesothelial cells and binds to $\alpha_{4} \beta_{1}$-integrin on ovarian carcinoma cells. Function-blocking antibodies directed against vascular cell adhesion molecule- 1 and $\alpha_{4} \beta_{1}$-integrin block migration and metastasis in a xenograft model. ${ }^{72}$ The role of the vitronectin receptor, $\alpha_{v} \beta_{3}$-integrin, in ovarian cancer metastasis is less clear. Although initially it was thought to be expressed on aggressive ovarian cancer cells, ${ }^{73,74}$ recent data question this assertion and suggest that it is expressed on well differentiated tumors and acts as a tumor suppressor in ovarian cancer. ${ }^{75}$ Therefore, therapies aimed at blocking $\alpha_{\mathrm{v}} \beta_{3}$-integrin may prove to have detrimental effects.

The binding of ovarian carcinoma cells to mesothelial cells is not only mediated by integrins, but also by CD44, the principal cell surface receptor for hyaluronic acid. The propensity of ovarian carcinoma cells to bind to peritoneal mesothelium can be partly inhibited by a neutralizing anti-CD44 antibody. ${ }^{76}$ Furthermore, in xenograft studies, the anti-CD44 antibody inhibits implantation to the peritoneal cavity of mice, but, since colony size was reported to be similar in antibody and control treated mice, the antibody does not seem to have an effect on proliferation. ${ }^{77}$ Of interest is that CD44 is also a stem cell marker. The possible role of cells with stem cell-like characteristics in ovarian carcinoma will be discussed later in this section.

When ovarian carcinoma cells attach to mesothelial cells, the cancer cells up-regulate MMP-2, which then cleaves the extracellular matrix proteins fibronectin and vitronectin into smaller fragments. The cancer cells then adhere much more strongly to these smaller fragments, using the fibronectin ( $\alpha_{5} \beta_{1}$-integrin) and vitronectin $\left(\alpha_{\vee} \beta_{3^{-}}\right.$ integrin) receptors. A one-time early treatment with a MMP inhibitor significantly reduced tumor weight and metastasis in mouse xenograft models, although the repeated treatment of established tumors had a minimal effect on tumor burden. ${ }^{70,78}$ These results suggest that MMP-2 is more important in early adhesion and early metastasis. They may also explain, at least in part, why potent MMP inhibitors failed in the clinic, since the patients treated had recurrent, chemoresistant disease, which is less dependent on MMP-2/9 expression. Although MMP-2 seems to be produced by the cancer cells, another type IV collagenase, MMP-9, is produced by host cells. Ovarian tumor cells grown in nude mice lacking the MMP-9 gene show impaired macrophage infiltration, angiogenesis, and tumor growth. However, when $\mathrm{MMP}_{-} \mathrm{9}^{+/+}$macrophages are injected into the MMP-9 knockout mice the tumors grow very efficiently. ${ }^{79}$

Invasion of the mesothelium is an early step of ovarian carcinoma metastasis. It can be mimicked using a new three-dimensional culture model (reviewed by Kenny et $\mathrm{al}^{69}$ ) that is composed of primary human mesothelial cells and primary human fibroblasts from the same patient suspended in an extracellular matrix. With the three-dimensional model, it was found that an intact mesothelial cell layer can very efficiently inhibit the invasion of ovarian carcinoma cells, suggesting that mesothelial cells can delay ovarian carcinoma attachment and invasion. ${ }^{69} \mathrm{~A}$ mechanism by which carcinoma cells overcome the effects of the mesothelial cells was proposed in a study using colon cancer cells, which found that tumor cells can induce mesothelial cell apoptosis by secreting Fas ligand, which then binds to the Fas receptor (CD95) on mesothelial cells. ${ }^{80}$ Interestingly, recent data has shown that the binding of Fas ligand to Fas receptor on ovarian cancer cells very significantly promotes tumor formation and tumor growth. This is contrary to the current perception that the function of Fas ligand is to cause apoptosis ${ }^{81}$ and raises the intriguing possibility that neutralizing the activity of Fas ligand could provide a novel therapeutic approach. Once the mesothelial cells are removed, the ovarian tumor cells adhere and invade forcefully through the extracellular matrix, which also promotes tumor growth. ${ }^{69}$ Of all of the extracellular matrix proteins present in the submesothelial basement membrane, primary ovarian carcinoma cells adhere preferentially to type I collagen, which can be blocked with an $\alpha_{2} \beta_{1}$ integrin antibody that inhibits the interaction of cancer cells with collagen. ${ }^{82}$

Another important protein in ovarian carcinoma metastasis is transglutaminase, an enzyme of prognostic significance that is overexpressed on ovarian carcinoma cells ${ }^{83}$ and is secreted into ascites. ${ }^{84}$ Transglutaminase 2 
modulates the extracellular matrix through $\mathrm{Ca}^{2+}$-dependent protein cross-linking and strengthens integrin-dependent cell adhesion. Transglutaminase-2 also induces the degradation of protein phosphatase-2, thereby activating the transcription factor CAMP response element binding protein, which regulates MMP-2 activity through a cAMP response element binding protein binding site in the MMP-2 promoter. ${ }^{85}$ In addition, it promotes EMT and enhances ovarian tumor metastasis by activating oncogenic signaling. ${ }^{86}$ Systemic inhibition of transglutaminase with a novel liposomal delivery of small interfering RNA significantly reduces tumor growth in both chemotherapy-sensitive and -resistant tumors. This effect was explained by a reduction in angiogenesis and increased apoptosis as well as decreased tumor cell attachment and invasion. ${ }^{83}$

\section{Late Metastasis: Tumors Transforming the Secondary Site}

The process of early metastasis depends on a well-coordinated process of adhesion and proteolysis, which allows the ovarian carcinoma cell to establish an outpost on the omentum and peritoneum. Although early metastasis is very well studied because of the availability of appropriate models, less is known about what happens after the ovarian cancer cells have implanted. We know from research into the biology of colon and breast cancer that once tumors reach a certain size they require new blood vessels, because diffusion alone can no longer provide the nutrients required for the growing tumor. As can be seen in Figure 2E, ovarian cancer implants attract new blood vessels to support their growth. A group of VEGFs stimulate vascular and lymphatic endothelium to form new blood and lymphatic vessels and also regulate their permeability. VEGFs A, B, and C and placental growth factor bind in overlapping affinities to three receptor tyrosine kinases, VEGF receptor 1 (VEGFR1) (flt-1), VEGFR2 (KDR), and VEGFR3, which are expressed on endothelial cells. High levels of VEGF in serum and ascites, and high VEGF expression on ovarian carcinoma tumors, have been associated with ovarian tumor progression and poor prognosis. ${ }^{87}$ VEGFRs were initially found on endothelial cells, but recent evidence suggests that they are also present on ovarian cancer cells. Inhibition of human VEGFR2 in an ovarian cancer xenograft model inhibited tumor growth by blocking the VEGFR2 on the human tumor cells. When the human antibody was combined with a murine antibody targeting host VEGFR2 on endothelial cells, there was an additive effect, suggesting both an autocrine and paracrine VEGF/VEGFR2 loop in ovarian cancer. ${ }^{88}$ It was also recently shown that the VEGFA/VEGFR2 ligand receptor pair protects ovarian cancer spheroids floating in ascites from anoikis and allows their survival in suspension. ${ }^{89}$

Several VEGF/VEGFR inhibitory agents are in clinical testing and early results are promising. Tests with a murine anti-human VEGF monoclonal antibody, the parent antibody of bevacizumab, inhibited ascites formation in xenograft models. Clinical testing of the humanized mu- rine antibody in phase I and II trials is showing response rates between 16 and $24 \%$ in recurrent ovarian carcino$\mathrm{ma}^{90}$ and preliminary phase III results from a study (GOG number 218) in the adjuvant setting (immediately after surgery) have just been released. Patients given an adjuvant treatment of carboplatin, taxol for 1 cycle, followed by bevacizumab, carboplatin, and Taxol for 5 cycles, and then maintenance therapy with bevacizumab for $15 \mathrm{ad}$ ditional cycles, showed a 4 months improvement in progression-free survival. There was no difference in progression-free survival when bevacizumab was given with carboplatinum and Taxol "only" during the initial adjuvant treatment and the maintenance therapy with bevacizumab was omitted. These results suggest that the regrowth of disease is delayed if VEGF is depleted from the tumor for a prolonged period of time.

Insights into late ovarian carcinoma metastases have also come from microarray studies that have compared the primary and metastatic tumor, reflecting advanced metastasis. In 1992 a report established that most ovarian carcinomas are clonal. ${ }^{91}$ Using the Affymetrix U 95 gene array, which contains 12,000 genes, Hibbs et al ${ }^{92}$ found only 64 genes and Adib et $a^{93}$ found only 35 genes that showed alterations in expression from the primary tumors to their metastases. This led both teams to conclude that the primary tumor and its corresponding metastases are essentially the same. These conclusions were confirmed by comparative genomic hybridization, ${ }^{94}$ and recently a high-resolution SNP analysis ${ }^{31}$ proved that the genetic alterations were similar in the primary tumors and their respective metastases. One explanation for these findings is that the metastatic process in ovarian carcinoma is not as complex as it is in other tumors because it "only" involves passive detachment from the primary tumor through the flow of peritoneal fluid and reattachment of cancer cells to the peritoneum/omentum. The alternative explanation is that most of the metastatic potential of the ovarian carcinoma cells already exists in the genetic changes present in the primary tumor and, therefore, it depends less on metastasis related selection pressure. This hypothesis was further refined by an elegant study from Khalique et al ${ }^{95}$ who evaluated clonal evolution between primary ovarian tumors and their metastasis using parsimony tree analysis, a software usually used to understand the evolution of animal species. They found that all metastases closely resemble the primary tumor and that different cancer clones within the primary tumor can give rise to metastasis.

The findings in ovarian carcinoma are in line with studies involving other cancers, including a study analyzing various primary tumors (eg, breast, medulloblastoma, prostate) in which a 17-gene signature in the primary tumor predicted metastases and prognosis. ${ }^{96}$ Another study in colon cancer, using full genomic sequencing of primary colon cancers and corresponding liver metastases, showed no new mutations in the metastases, implying that new mutations are not required for a tumor cell to leave the primary tumor and seed to a distant site. ${ }^{97}$ The fact that most primary tumors and metastasis have similar genetic changes has several potential implications for the diagnosis and treatment of serous ovarian carcinomas. It 
suggests that serous ovarian carcinoma is able to metastasize quickly once completely transformed. This was confirmed by mathematic modeling based on clinical data from BRCA-positive patients undergoing a prophylactic oophorectomy who had small, subclinical cancers. Brown and Palmer showed that these occult tumors double every 2.5 months and that serous tumors disseminate when they are only $3 \mathrm{~cm}$ in size. ${ }^{29}$ This makes screening for early ovarian carcinoma much more difficult because the time available for finding an early lesion by screening is very short. ${ }^{29,98,99}$ However, it also suggests that if the right genetic lesions are targeted therapeutically it will be possible to eradicate both the primary tumor and the metastatic tumor.

Ovarian carcinomas are heterogenous tumors and contain a small number of cells with stem cell-like characteristics, such as expressing Oct4, Nestin, and c-kit/ CD117. When ovarian cancer cells that express these stem cell-related molecules are isolated from ascites, they have the ability to grow in an anchorage-independent manner in vitro and form in vivo tumors that are able to metastasize. ${ }^{100}$ Szotek et al $^{101}$ identified a subpopulation of ovarian carcinoma cells that have the ability to efflux the lipophylic dye Hoechst 33342. These cells express c-kit/CD117 and also the hyaluronate receptor CD44, markers previously described in cancer stem cells from other solid tumors. Cells that express these markers are highly tumorigenic in mice and chemotherapy-resistant when compared with the noneffluxing cells. The detection of ovarian carcinoma stem cells with an ability to self-renew and high epithelial plasticity raises the interesting possibility that these cells have higher metastatic efficiency and might be responsible for the majority of metastasizing ovarian carcinoma cells. Their increased chemoresistance to standard carboplatin and Taxol chemotherapy also suggests that the successful eradication of these cells would require a non-cross-resistant chemotherapy regimen.

\section{Concluding Remarks}

Ovarian carcinoma is a rare disease, and therefore, to find new and better treatments, we will have to take a nontraditional path. Unlike research in breast and colon cancer (which are, respectively, 11 and 7 times more common than ovarian carcinoma), research in ovarian carcinoma presents limited opportunities for large phase III trials. Therefore, new drugs should be characterized through translational studies that use several methods in parallel, including bioinformatics, cell lines, three-dimensional models, and xenograft and genetic mouse models. These studies should then be followed by extended phase II clinical protocols using innovative trial designs. In addition, we may also have to change how new agents are validated preclinically. Many new drugs are tested in a metastasis prevention setting; tumor cells are injected into nude mice and treatment with the new compound is started a few days later. Yet most clinical phase II trials examine a compound for activity against a recurrent, widely metastasized, multidrug-resistant cancer. A pos- sible improvement could be to allow the cells to grow and disseminate in the mouse first, treat with standard chemotherapy, and then test the new drug.

The biological behavior of ovarian carcinoma gives us special opportunities for treatment, since most of the tumors are confined within the peritoneal cavity. The seclusion of the abdominal cavity constitutes an unusually defined therapeutic space and intraperitoneal treatment has already proven more efficient than conventional intravenous treatment. Given the genetic similarity of abdominal ovarian tumors, an appropriate treatment target has, theoretically, the chance to shrink all tumors simultaneously and offer a significant improvement in the treatment of ovarian cancer.

\section{Acknowledgments}

I greatly appreciate the comments on the manuscript from my colleagues at the University of Chicago: Dr. Hilary Kenny, Dr. Anirban Mitra, and Dr. Arthur Herbst, (Department of Obstetrics and Gynecology), Dr. Anthony Montag (Department of Pathology), and Dr. Marcus Peter (The Ben May Department for Cancer Research). I am very thankful to Gail Isenberg's help in editing the manuscript and assembling the figures. Last, I want to thank the current and former members of the Lengyel laboratory for their dedication to ovarian cancer research.

\section{References}

1. Jemal A, Siegel R, Ward E, Murray T, Xu J, Smigal C, Thun M: Cancer statistics, 2009. CA Cancer J Clin 2009, 59:225-249

2. Eisenkop S, Spirtos NM: The clinical significance of occult macroscopically positive retroperitoneal nodes in patients with epithelial ovarian cancer. Gynecol Oncol 2001, 82:143-149

3. Bristow RE, del Carmen M, Kaufman H, Montz FJ: Radical oophorectomy with primary stapled colorectal anastomosis for resection of locally advanced epithelial ovarian cancer. J Am Coll Surg 2003, 197:565-574

4. Bristow RE, Tomacruz RS, Armstrong DK, Trimble EL, Montz FJ: Survival effect of maximal cytoreductive surgery for advanced ovarian carcinoma during the platinum era: a meta-analysis. J Clin Oncol 2002, 20:1248-1259

5. Winter WE, Maxwell L, Tian C, Carlson JW, Ozols RF, Rose P, Markmann M, Armstrong DK, Muggia F, McGuire WP: Prognostic factors for stage III epithelial ovarian cancer: a Gynecologic Oncology Group study. J Clin Oncol 2007, 25:3621-3627

6. Armstrong DK, Bundy B, Wenzel L, Huang H, Baergen R, Lele S, Copeland LJ, Walker JL, Burger RA: Intraperitoneal cisplatin and paclitaxel in ovarian cancer. N Engl J Med 2006, 353:34-43

7. Tavassoli FA and Devilee P: Tumors of the ovary and peritoneum. Tumors of the Breast and Female Genital Organs. Edited by P Kleihues and L Sobin. Lyon, France, IARC Press, 2003, pp. 113-203

8. Marquez RT, Baggerly KA, Patterson AP, Liu J, Broaddus R, Frumovitz M, Atkinson EN, Smith DI, Hartmann L, Fishman D, Berchuk A, Whitaker R, Gershenson D, Mills GB, Bast RC, Lu K: Patterns of gene expression in different histotypes of epithelial ovarian cancer correlate with those in normal fallopian tube, endometrium, and colon. Clin Cancer Res 2005, 11:6116-6126

9. Fathalla M: Factors in the causation and incidence of ovarian cancer. Obstetr Gynecol Survey 1972, 27:751-768

10. Auersperg N, Edelson MI, Mok SC, Johnson SW, Hamilton TC: The biology of ovarian cancer. Semin Oncol 1998, 25:281-304

11. Cheng W, Liu J, Yoshida H, Rosen D, Naora H: Lineage infidelity of epithelial ovarian cancers is controlled by HOX genes that specify 
regional identity in the reproductive tract. Nat Med 2008, 11:531-537

12. Naora $\mathrm{H}$ : Developmental patterning in the wrong context: the paradox of epithelial ovarian cancer. Cell Cycle 2005, 4:1033-1035

13. Piek JM, van Diest PJ, Zweemer RP, Jansen JW, Poort-Keesom RJ, Menko FH, Gille JJ, Jongsma AP, Pals G, Kenemans P, Verheijen $\mathrm{RH}$ : Diagnostic changes in prophylactically removed fallopian tubes of women predisposed to developing ovarian cancer. J Pathol 2001, 195:451-456

14. Powell B, Kenley E, Chen LM, Crawford B, McLennan J, Zaloudek C, Komaromy M, Beattie M, Ziegler J: Risk-reducing salpingo-ophorectomy in BRCA mutation carriers: role of serial sectioning in the detection of occult malignancy. J Clin Oncol 2005, 23:127-132

15. Kindelberger DW, Lee Y, Miron A, Hirsch MS, Feltmate C, Medeiros F, Callahan MJ, Garner EO, Gordon RW, Birch C, Berkowitz RS, Muto MG, Crum CP: Intraepithelial carcinoma of the fimbria and pelvic serous carcinoma: evidence for a causal relationship. Am J Surg Pathol 2007, 31:161-169

16. Folkins $\mathrm{AK}$, Jarboe $\mathrm{EA}$, Roh $\mathrm{MH}$, Crum $\mathrm{CP}$ : Precursor to pelvic serous carcinoma and their clinical implications. Gynecol Oncol 2009, 113:391-396

17. Dubeau L: The cell of origin of ovarian epithelial tumors. Lancet Oncol 2008, 9:1191-1197

18. Auersperg N, Woo MMM, Gilks CB: The origin of ovarian carcinomas: a developmental view. Gynecol Oncol 2008, 110:452-454

19. Kurman R, Shih I-M: The origin and pathogenesis of epithelial ovarian cancer: a proposed unifying theory. Am J Surg Pathol 2010, 34:433-443

20. Singer G, Oldt R, Cohen Y, Wang B, Sidransky D, Kurman R, Shih I-M: Mutations in B-raf and K-ras characterize the development of low-grade ovarion serous carcinoma. J Natl Cancer Inst 2003, 95:484-486

21. Shih I-M, Kurman R: Ovarian tumorigenesis: a proposed model based on morpholgical and molecular genetic analysis. Am J Pathol 2004, 164:1511-1518

22. Gershenson D, Sun CC, Lu K, Coleman RL, Sood AK, Malpica A, Deavers M, Silva EG, Bodurka-Bevers D: Clinical behavior of stage II-IV low-grade serous carcinoma of the ovary. Obstet Gynecol 2006, 108:361-368

23. Kinzler KW, Vogelstein B: Lessons from hereditary colorectal cancer. Cell 1996, 87:159-170

24. Hsu C-Y, Bristow RE, Cha MS, Wang B, Ho CL, Kurman R, Wang TL, Shih I-M: Characterization of active mitogen-activated protein kinase in ovarian serous carcinomas. Clin Cancer Res 2004, 10:6432-6436

25. Prowse A, Manek S, Varma R, Liu J, Godwin AK, Maher E, Tomlinson I, Kennedy S: Molecular genetic evidence that endometriosis is a precursor of ovarian cancer. Int J Cancer 2006, 1189:556-562

26. Banz C, Ungethuem U, Kuban RJ, Diedrich K, Lengyel E, Hornung $\mathrm{D}$ : The molecular signature of endometriosis-associated endometroid ovarian cancer differs significantly from endometriosis-independent endometroid ovarian cancer. Fertil Steril 2009, doi: 10.1016/j.fertnstert.2009.06.039

27. Dinulescu D, Ince T, Quade B, Shafer S, Crowley D, Jacks T: Role of K-ras and PTEN in the development of mouse models of endometriosis and endometrioid ovarin cancer. Nat Med 2005, 11:63-70

28. Romero I, Gordon I, Jagadeeswaran S, Mui KL, Lee WS, Dinulescu D, Krausz T, Kim H, Gilliam M, Lengyel E: Effects of oral contraceptives or a gonadotropin-releasing hormone agonist on ovarian carcinogenesis in genetically engineered mice. Cancer Prev Res 2009, 2:792-799

29. Brown PO, Palmer C: The preclinical natural history of serous ovarian cancer: defining the target for early detection. PLoS Med 2009, $6: 1-11$

30. Kuo KT, Guan B, Feng Y, Mao TL, Chen X, Jinawath N, Wang Y, Kurman R, Shih I-M, Wang TL: Analysis of DNA copy number alterations in ovarian serous tumors identified new molecular genetic changes in low-grade and high-grade carcnomas. Cancer Res 2009, 69:4036-4042

31. Haverty PM, Hon LS, Kaminker JS, Chant J, Zhang Z: High resolution analysis of copy number alterations and associated expression changes in ovarian tumors. BMC Med Genomics 2009, 2:21

32. Flesken-Nikitin A, Choi K, Eng JP, Shmidt EN, Nikitin A: Induction of carcinogenesis by concurrent inactivation of p53 and Rb1 in the mouse ovarian surface epithelium. Cancer Res 2003, 63:3459-3463
33. Kohler MF, Marks JR, Wiseman R, Jacobs IJ, Davidoff AM, ClarkePearson DL, Soper JT, Bast RC, Berchuk A: Spectrum of mutation and frequency of allelic deletion of the p53 gene in ovarian cancer J Natl Cancer Inst 1993, 85:1513-1519

34. Singer G, Stöhr R, Cope L, Dehari R, Hartman A, Cao DF, Wang TL, Kurman R, Shih I-M: Patterns of p53 mutations separate ovarian serous borderline tumors and low- and high-grade carcinomas and provide support for a new model of ovarian carcinogenesis: a mutational analysis with immunohistochemical correlation. Am J Surg Pathol 2005, 29:218-224

35. Milner BJ, Allan LA, Eccles DM, Kitchener HC, Leonard RCF, Kelly KF, Parkin DE, Haites NE: p53 mutation is a common genetic event in ovarian carcinoma. Cancer Res 1993, 53:2128-2132

36. Zeimet AG, Marth C: Why did p53 gene therapy fail in ovarian cancer? Lancet Oncol 2003, 4:415-419

37. Cheng JQ, Godwin AK, Bellacosa A, Taguchi T, Franke TF, Hamilton TC, Tsichlis PN, Testa J: AKT2, a putative oncogene encoding a member of a subfamily of protein-serine/threonine kinases, is amplified in human ovarain carcinomas. Proc Natl Acad Sci USA 1992 89:9267-9271

38. Shayesteh L, Lu Y, Kuo W, Baldocchi R, Godfrey T, Collins C, Pinkel D, Powell B, Mills GB, Gray J: PIK3CA is implicated as an oncogene in ovarian cancer. Nat Genet 1999, 21:99-102

39. Kuo KT, Mao TL, Jones S, Veras E, Ayhan A, Wang TL, Glas R, Slamon DJ, Velculescu V, Kurman R, Shih I-M: Frequent activating mutations of PIK3CA in ovarian clear cell carcinoma. Am J Pathol 2009, 174:1597-1601

40. Gupta G, Massague J: Cancer metastasis: building a framework Cell 2006, 127:679-695

41. Tarin D, Price JE, Kettlewell MG, Souter RG, Vass AC, Crossley B Mechanism of human tumor metastasis studied in patients with peritoneovenous shunts. Cancer Res 1984, 44:3584-3592

42. Huber MA, Kraut N, Beug H: Molecular requirements for epithelialmesenchymal transition during tumor progression. Curr Opin Cell Biol 2006, 17:548-558

43. Cavallaro $U$, Christofori G: Cell adhesion and signalling by cadherins and IG-cams in cancer. Nat Rev 2004, 4:118-132

44. Kalluri R, Weinberg RA: The basics of epithelial-mesenchymal transition. J Clin Invest 2009, 119:1420-1429

45. Veatch AL, Carson LF, Ramakrishnan S: Differential expression of the cell-cell adhesion molecule E-cadherin in ascites and solid human ovarian tumor cells. Int J Cancer 1994, 58:393-399

46. Darai E, Scoazec JY, Walker-Combrouze F, Mlika-Cabanne N, Feld mann G, Madelenat P, Potet F: Expression of cadherins in benign, borderline, and malignant ovarian epithelial tumors: a clinicopathologic study of 60 cases. Hum Pathol 1997, 28:922-928

47. Elloul S, Elstrand MB, Nesland JM, Trope CG, Kvalheim G, Goldberg I, Reich R, Davidson B: Snail, Slug, and Smad-interacting protein 1 as novel parameters of disease aggressiveness in metastatic ovarian and breast carcinoma. Cancer 2005, 103:1631-1643

48. Ahmed N, Thompson EW, Quinn MA: Epithelial-mesenchymal interconversions in normal ovarian surface epithelium and ovarian carcinomas: an exception to the norm. J Cell Physiol 2007 213:581-588

49. Hudson LG, Zeineldin R, Stack MS: Phenotypic plasticity of neoplastic ovarian epithelium: unique cadherin profiles in tumor progression. Clin Exp Metastasis 2008, 25:643-655

50. Patel IS, Madan P, Getsios S, Bertrand M, MacCalman C: Cadherin switching in ovarian cancer progression. Int J Cancer 2003 106:172-177

51. Imai T, Horiuchi A, Wang C, Oka K, Ohira S, Nikaido T, Konishi I: Hypoxia attenuates the expression of E-cadherin via up-regulation of SNAIL in ovarian carcinoma cells. Am J Pathol 2003, 163:1437-1447

52. Symowicz J, Adley BP, Gleason KJ, Johnson JJ, Ghosh S, Fishman DA, Hudson LG, Stack MS: Engagement of collagen-binding integrins promotes matrix metalloproteinase-9-dependent E-cadherin ectodomain shedding in ovarian carcinoma cells. Cancer Res 2007, 67:2030-2039

53. Burleson KM, Hansen LK, Skubitz AP: Ovarian carcinoma spheroids disaggregate on type I collagen and invade live human mesothelia cell monolayers. Clin Exp Metastasis 2004, 21:685-697

54. Sawada K, Radjabi AR, Shinomiya N, Kistner E, Kenny HA, Salgia R, Yamada SD, Vande Woude GF, Tretiakova MS, Lengyel E: C-Met overexpression is a prognostic factor in ovarian cancer and an 
effective target for inhibition of peritoneal dissemination and invasion. Cancer Res 2007, 67:1670-1680

55. Cannistra SA: Cancer of the ovary. N Engl J Med 2004, 351:2519-2529

56. Byrne A, Ross L, Holash J, Nakanishi M, Hu L, Yancopoulos G, Jaffe RB: Vascular endothelial growth factor-Trap decreases tumor burden, inhibits ascites, and causes dramtic vascular remodeling in an ovarian cancer model. Clin Cancer Res 2003, 9:5721-5728

57. Hu L, Hofman J, Holash J, Yancopoulos G, Sood AK, Jaffe RB: Vascular endothelial growth factor Trap combined with paclitaxel strikingly inhibits tumor and ascites, prolonging survival in a human ovarian cancer model. Clin Cancer Res 2005, 11:6966-6972

58. Burleson KM, Casey RC, Skubitz KM, Pambuccian SE, Oegema TR, Skubitz AP: Ovarian carcinoma ascites spheroids adhere to extracellular matrix components and mesothelial cell monolayers. Gynecol Oncol 2004, 93:170-181

59. Shield K, Riley C, Quinn MA, Rice GE, Ackland ML, Ahmed N: $\alpha_{2} \beta_{1}$-Integrin affects metastatic potential of ovarian carcinoma spheroids by supporting disaggregation and proteolysis. J Carcinog 2007, 6:11

60. Casey RC, Burleson KM, Skubitz KM, Pambuccian SE, Oegema TR, Ruff LE, Skubitz AP: $\beta_{1}$-Integrins regulate the formation and adhesion of ovarian carcinoma multicellular spheroids. Am J Pathol 2001, 159:2071-2080

61. Moss NM, Barbolina MV, Liu Y, Sun L, Munshi HG, Stack MS: Ovarian cancer cell detachment and multicellular aggregate formation are regulated by membrane type 1 matrix metalloproteinase: a potential role in I.p metastatic dissemination. Cancer Res 2009, 69:7121-7129

62. Davidson B, Goldberg I, Berner A, Nesland JM, Givant-Horwitz, Bryne M, Risberg B, Kristensen G, Trope C, Kopolovic J, Reich R: Expression of membrane-type 1,2, and 3 matrix metalloproteinases messenger RNA in ovarian carcinoma cells in serous effusion. Am $J$ Clin Pathol 2001, 115:517-524

63. Frankel A, Buckman R, Kerbel RS: Abrogation of Taxol-induced $\mathrm{G}_{2}-\mathrm{M}$ arrest and apoptosis in human ovarian cancer cells grown as multicellular spheroids. Cancer Res 1997, 57:2388-2393

64. Green SK, Francia G, Isidoro C, Kerbel RS: Antiadhesive antibodies targeting E-cadherin sensitize multicellular tumor spheroids to chemotherapy in vitro. Mol Cancer Ther 2004, 3:149-159

65. Sehouli J, Senyuva F, Fotopoulou C, Neumann U, Denkert C, Lichtenegger W, Gülten OÖ: Intra-abdominal tumor dissemination pattern and surgical outcome in 214 patients with primary ovarian cancer. J Surg Oncol 2009, 99:424-427

66. Daya D, McCaughy WT: Pathology of the peritoneum: a review of selected topics. Semin Diagn Pathol 1991, 8:277-289

67. Kenny HA, Krausz T, Yamada SD, Lengyel E: Use of a novel 3D culture model to elucidate the role of mesothelial cells, fibroblasts and extra-cellular matrices on adhesion and invasion of ovarian cancer cells. Int J Cancer 2007, 121:1463-1472

68. Witz CA, Montoya-Rodriguez I, Cho S, Centonze V, Bonewald L, Schenken RS: Composition of the extracellular matrix of the peritoneum. J Soc Gynecol Investig 2001, 8:299-304

69. Kenny HA, Dogan S, Zillhardt M, Mitra AK, Yamada SD, Krausz T, Lengyel $\mathrm{E}$ : Organotypic models of metastasis: a three dimensional culture mimicking the human peritoneum and omentum for the study of the early steps of ovarian cancer metastasis. Ovarian Cancer. Edited by MS Stack and DA Fishman. New York, Springer, 2009, pp. 335-351

70. Kenny HA, Kaur S, Coussens L, Lengyel E: The initial steps of ovarian cancer cell metastasis are mediated by MMP-2 cleavage of vitronectin and fibronectin. J Clin Invest 2008, 118:1367-1379

71. Strobel T, Cannistra SA: $\beta_{1}$-Integrins partly mediate binding of ovarian cancer cells to peritoneal mesothelium in vitro. Gynecol Oncol 1999, 73:362-367

72. Slack-Davis JK, Atkins KA, Harrer C, Hershey ED, Conaway M: Vascular cell adhesion molecule-1 is a regulator of ovarian cancer peritoneal metastasis. Cancer Res 2009, 33:49-54

73. Cannistra SA, Ottensmeier C, Niloff J, Orta B, DiCarlo J: Expression and function of $\beta_{1}$ and $\alpha_{v} \beta_{3}$ integrins in ovarian cancer. Gynecol Oncol 1995, 58:216-225

74. Lössner D, Abou-Ajram C, Benge A, and Reuning U: Integrin $\alpha_{v} \beta_{3}$ mediates up-regulation of epidermal growth-factor receptor expres- sion and activity in human ovarian cancer cells. Int $\mathrm{J}$ Biochem Cell Biol 2008, 40:2746-2761

75. Kaur S, Kenny HA, Jagadeeswaran S, Zillhardt M, Montag A, Kistner E, Yamada SD, Mitra AK, Lengyel E: $\beta_{3}$-Integrin expression on tumor cells inhibits tumor progression, reduces metastasis, and is associated with a favorable prognosis in patients with ovarian cancer. Am $J$ Pathol 2009, 175:2184-2196

76. Cannistra SA, Kansas GS, Niloff J, DeFranzo B, Kim Y, Ottensmeier C: Binding of ovarian cancer cells to peritoneal mesothelium in vitro is partly mediated by CD44H. Cancer Res 1993, 53:3830-3838

77. Strobel T, Swanson L, Cannistra SA: In vivo inhibition of CD44 limits intra-abdominal spread of a human ovarian cancer xenograft in nude mice: a novel role for CD 44 in the process of peritoneal implantation. Cancer Res 1997, 57:1228-1232

78. Kenny HA, Lengyel E: MMP-2 functions as an early response protein in ovarian cancer metastasis. Cell Cycle 2009, 8:683-688

79. Huang S, Van Arsdall M, Tedjarti S, McCarthy M, Wu W, Langley R, Fidler IJ: Contributions of stromal metalloproteinase-9 to angiogenesis and growth of human ovarian carcinoma in mice. J Natl Cancer Inst 2002, 94:1134-1142

80. Heath R, Jayne D, O'Leary R, Morrison E, Guillou P: Tumor-induced apoptosis in human mesothelial cells: a mechanism of peritoneal invasion by Fas Ligand/Fas interaction. Br J Cancer 2004, 90:1437-1442

81. Chen L, Park SM, Tumanov AV, Hau A, Sawada K, Feig C, Turner JR, Fu YX, Romero I, Lengyel E, Peter ME: CD95/Fas promotes tumor growth. Nature 2010, 465(7297):492-496

82. Moser TL, Pizzo SV, Bafetti L, Fishman DA, Stack MS: Evidence for preferential adhesion of ovarian epithelial carcinoma cells to type collagen mediated by the $\alpha_{2} \beta_{1}$ integrin. Int J Cancer 1996, 67:695-701

83. Hwang JE, Mangala LS, Fok JY, Lin YG, Merritt W, Spannuth W, Nick AM, Fiterman DJ, Vivas-Mejia PE, Deavers M, Coleman RL, LopezBerestein G, Mehta K, Sood AK: Clinical and biological significance of tissue transglutaminase in ovarian carcinoma. Cancer Res 2008 68:5849-5858

84. Satpathy M, Cao L, Pincheira R, Emerson R, Bigsby R, Nakshatri H, Matei D: Enhanced peritoneal ovarian tumor dissemination by tissue transglutaminase. Cancer Res 2007, 67:7194-7202

85. Satpathy M, Shao M, Emerson R, Donner DB, Matei D: Tissue transglutaminase regulates matrix metalloproteinase-2 in ovarian cancer by modulating CAMP-response element-binding protein activity. J Biol Chem 2009, 284:15390-15399

86. Shao M, Cao L, Shen C, Satpathy M, Chelladurai B, Bigsby RM, Nakshatri H, Matei D: Epithelial-to-mesenchymal transition and ovarian tumor progression induced by tissue transglutaminase. Cancer Res 2009, 69:9192-9201

87. Nishida N, Yano H, Komai K, Nishida T, Kamura T, Kojiro M: Vascular endothelial growth factor $\mathrm{C}$ and vascular endothelial growth factor receptor 2 are related closely to the prognosis of patients with ovarian carcinoma. Cancer 2004, 101:1364-1374

88. Spannuth W. Nick AM, Jennings N, Armaiz-Pena G, Mangala L, Danes CG, Lin Y, Merritt W, Thaker P, Kamar A, Han L, Tonra JR, Coleman RL, Ellis LM, Sood AK: Functional significance of VEGFR-2 on ovarian cancer cells. Int J Cancer 2009, 124:1045-1053

89. Sher I, Adham SA, Petrik J, Coomber BL: Autocrine VEGF-A/KDR loop protects epithelial ovarian carcinoma cells from anoikis. Int $J$ Cancer 2009, 124:553-561

90. Garcia A, Hirte H, Fleming G, Yang D, Tsao-wei D, Roman L, Groshen S, Swenson S, Markland F, Gandara D, Scudder S, Morgan $\mathrm{R}$, Chen H, Lenz HJ, Oza A: Phase II clinical trial of bevacizumab and low-dose metronomic oral cyclophosphamide in recurrent ovarian cancer: a trial of the california, chicago, and princess hospital phase II consortia. J Clin Oncol 2008, 26:76-82

91. Jacobs IJ, Kohler MF, Wiseman R, Marks JR, Whitaker R, Kerns BAJ, Humphrey P, Berchuk A, Ponder BAJ, Bast RC: Clonal origin of epithelial ovarian carcinoma: analysis by loss of heterozygosity, p53 mutation, and X-chromosome inactivation. J Natl Cancer Inst 1992 84:1793-1798

92. Hibbs K, Skubitz KM, Pambuccian SE, Casey RC, Burleson KM Oegema TR, Thiele J, Grindle SM, Bliss RL, Skubitz AP: Differential gene expression in ovarian carcinoma. Am J Pathol 2004, 165:397-414

93. Adib T, Henderson S, Perrett C, Bourmpoulia D, Lederman J, Boshoff $\mathrm{C}$ : Predicting biomarkers for ovarian cancer using geneexpression microarrays. Br J Cancer 2004, 90:686-692

94. Israeli O, Gotlieb WH, Friedman E, Korach J, Friedman E, Goldman 
B, Zeltser A, Ben-Baruch G, Rienstein S, Aviram-Goldring A: Genomic analyses of primary and metastatic serous epithelial ovarian cancer. Cancer Genet Cytogenet 2004, 154:16-21

95. Khalique L, Ayhan A, Whittaker JC, Singh N, Jacobs IJ, Gayther SA, Ramus SJ: The clonal evolution of metastases from primary serous epithelial ovarian cancers. Int J Cancer 2009, 124:1579-1586

96. Ramawamy S, Ross KN, Lander ES, Golub TR: A molecular signature of metastasis in primary solid tumors. Nat Genet 2003, 33:49-54

97. Jones S, Chen W-D, Parmigiani G, Diehl F, Beerenwinkel N, Antal T, Traulsen A, Nowak MA, Siegel C, Velculescu V, Kinzler KW, Vogelstein B, Willis J, Markowitz S: Comparative lesion sequencing provides insights into tumor evolution. Proc Natl Acad Sci USA 2008, 105:4283-4288
98. Burger RA: A new model of ovarian carcinogenesis may influence early detection strategies. Am J Obstet Gynecol 2008, 198:349-350

99. Kurman R, Visvanathan K, Roden R, Wu TC, Shih I-M: Early detection and treatment of ovarian cancer: shifting from early stage to minimal volume of disease based on a new model of carcinogenesis. Am J Obstet Gynecol 2008, 351-356

100. Bapat SA, Mali AM, Koppikar CB, Kurrey NK: Stem and progenitorlike cells contribute to the aggressive behavior of human epithelial ovarian cancer. Cancer Res 2005, 65:3025-3029

101. Szotek PP, Pieretti-Vanmarcke R, Masiakos PT, Dinulescu D, Connolly D, Foster R, Dombkowski D, Preffer F, MacLaughlin DT, Donahoe P: Ovarian cancer side populations defines cells with stem cell-like characteristics and Mullerian Inhibiting Substance responsiveness. Proc Natl Acad Sci USA 2006, 103:11154-11159 